\title{
On the Value of the Intellectual Commons
}

\author{
James Wilson, Centre for Philosophy, Justice and Health, \\ and Comprehensive Biomedical Research Centre, UCL \\ james-gs.wilson@ucl.ac.uk
}

Forthcoming in New Frontiers in the Philosophy of Intellectual Property (ed. Annabelle Lever, Cambridge University Press, 2012).

\section{Introduction}

When we talk about intellectual property, it is often implicitly assumed that we are talking about private intellectual property. However, private property and the idea of private ownership do not exhaust the possibilities for accounts of ownership and of property. There are other ways that ownership can operate, such as common property. A resource is common property if its use is 'governed by rules whose point is to make them available for use by all or any members of the society.',

As the economic importance of intellectual property (IP) has increased, the appropriate direction of IP policy has received extensive attention in the law and economics literatures: much of this debate has focused on the relative merits of open versus closed approaches to innovation, and of commons based versus private property approaches. Common ownership of physical resources such as fields and lakes has long been thought problematic. In Hardin's classic example of the tragedy of the commons, people will tend to overgraze a field which is held in common, for it is in the interest of each shepherd to ensure that they have as many sheep as possible, and that each of their sheep are well-grazed; however if all (or most) shepherds behave in this way, then the commons will get overgrazed, and its ability to support sheep will soon be destroyed. ${ }^{2}$ However the considerations which make common ownership

1 J. Waldron, 'Property and Ownership', The Stanford Encyclopedia of Philosophy (Winter 2010 Edition),

Edward N. Zalta (ed.), URL = <http://plato.stanford.edu/archives/win2010/entries/property/>. Or, in Lawrence Lessig's words, 'The essence [of the commons] is that no one exercises the core of a property right with respect to these resources - the exclusive right to choose whether the resource is made available to others.' L. Lessig, The Future of Ideas: The Fate of the Commons in a Connected World (New York: Vintage, 2002), p.19.

2 See G. Hardin. 'The tragedy of the commons,' Science 162(3859) (1968): 1243-1248. It is worth pointing out - as Ostrom and others have argued - that even where rival goods are held in common, the tendency towards a tragedy of the commons is by no means inevitable; rather there are various ways of regulating the commons which can successfully protect and sustain it. See further E. Ostrom, Governing the Commons: The Evolution of Institutions for Collective Action (Cambridge: Cambridge University Press, 1990). 
problematic in the case of real property do not apply in the case of ownership of ideas. Ideas, unlike physical objects are nonrival: one person's use of them does not interfere with anyone else's. For this reason, and for others we shall explore later, it is much more uncertain whether and if so when private property solutions are to be preferred to common property solutions in the case of IP.

Philosophers have so far contributed little to these debates on the optimal regulation of ownership of IP. This chapter analyses what contribution philosophy can expect to make. I begin in section 2 by distinguishing two tasks that philosophy can attempt when it comes to the optimal regulation of IP: first, philosophers can devise a high level regulatory model for IP, explaining how, for example the ontology of ideas makes a difference to how we should regulate them, and what the overall goals are that we should have in an IP policy. Second, philosophers can attempt to make cogent and concrete policy suggestions on the basis of such a high level regulatory model. I argue that it is often extremely difficult to draw cogent and concrete policy proposals from even extremely good moral and political philosophy; and given the paucity of philosophical theorising so far about IP, it would be especially ambitious to expect philosophers now to construct theories which will have concrete and cogent policy implications. Hence this chapter focuses mostly on the first task.

Section 3 examines intellectual property from the perspective of moral rights. ${ }^{3}$ I argue that one significant contribution that philosophy can make is to show that there are no moral rights to own intellectual property; and that there are at least some cases where it is plausible to think that private intellectual property could violate the rights of those who are excluded by it.

Section 4 sets out some of the main goals that an optimal regulatory system for IP should encompass. I argue that there is no intrinsic value in restricting access to ideas: the sole reason in favour of having private intellectual property restrictions in intellectual property is that such restrictions create incentives which will speed the production of intellectually creative work. However there are a number of important values-in particular, liberty, efficient use of resources and equality-which will tend to conflict with intellectual property restrictions. The net result of these value conflicts is that private ownership of intellectual property should be thought of as a necessary evil; something that we should support only where the incentives thus provided are necessary for the supply of future ideas, and where using such incentives is a better way of juggling our various value commitments than other alternatives.

Section 5 examines what should follow from these claims about rights and goals for concrete IP policies. The answer is frustratingly little, owing to the complexity of the terrain, and the lack of data on the effectiveness of different models of incentivisation.

\section{Is Philosophy Useful for Thinking About Problems of Regulation?}

Philosophical thinking gains much of its power from its abstraction: philosophers typically

3 Moral rights are used here in the philosopher's sense of rights claims which are justifiable on moral rather than legal grounds, rather than as relating to the droit d'auteur. 
argue that they get to the heart of issues by stripping away contingent and irrelevant details, and focusing on schematic but clearly described scenarios-scenarios which are often very different from those we encounter in real life.

Even when we have a superb piece of moral or political philosophy which is widely believed to make great strides in solving the schematically described problems on which it focuses, it is often far from clear what implications the work has for what we should do, given our current circumstances. ${ }^{4}$ To give just one example of a very general problem, Rawls makes various abstractions and simplifications in A Theory of Justice, such as that he is concerned with a society in which everyone is a fully contributing member over the full course of their life; that there is no emigration or immigration; that everyone complies with the rules set out by the theory of justice; and that the account of justice only applies to the basic structure of society. ${ }^{5}$ In virtue of these simplifications and counter-to-fact stipulations, it is far from clear what implications Rawls' theory has for specific policy areas such as disability or intellectual property. Even if we could confidently derive such a policy implication, it is unclear if it would be a policy that we had good reason to adopt, all things considered. ${ }^{6}$

We can distinguish between two projects for philosophy in the regulation of IP: a less and a more ambitious. The first would be to provide a systematic theoretical account of the normative terrain, and the second to provide cogent and concrete policy recommendations on the basis of this theoretical account. This chapter aims to undertake the first task, and to examine the prospects for completing the second. I undertake the first task by examining IP from the fundamental orientation of moral rights, and from the perspective of what goals government policy should aim at when it comes to IP. However, as I shall argue in section 4, it is not entirely clear what the implications of this theoretical account are for concrete policy decisions: the regulatory problems are sufficiently complex, and the empirical data so

4 For two influential takes on this problem, see G. Brennan and P. Pettit, 'The feasibility issue," in The Oxford Handbook of Contemporary Philosophy, ed. F. Jackson and M. Smith (Oxford: Oxford University Press, 2005), pp. 258-279; A. Sen, 'What do we want from a theory of justice?', Journal of Philosophy 103(5) (2006): 215-238.

5 J. Rawls, A Theory of Justice, Revised Edition (Oxford: Oxford University Press, 1999).

6 Rawls himself was famously reluctant to draw specific policy conclusions from his theory of justice. In one of the very few interviews he gave, he answered the question 'When you look at current events, in general, do you think of them with the A Theory of Justice framework in mind?' as follows: "I'm sure that my view must affect in some manner how I see them, but I don't just ask what justice as fairness would say. That would be limiting. I don't see a political conception of justice as something that will tell me what to think. It's a great mistake to think of it as a device that will give you answers, that will deliver the answers to all sorts of questions when you want them. That is one reason I am reluctant to answer questions about specific political topics. It suggests the wrong idea: that we could have some theoretical way of doing that, which is usually not so at all. I think of justice as fairness as trying to answer certain specific though basic questions. Its scope is limited." (S. Aybar, J. Harlan and W. Lee, 'John Rawls: For The Record,' Harvard Review of Philosophy 1 (1991): 38-48, at p.45. Online at http://www.hcs.harvard.edu/ hrp/issues/1991/Rawls.pdf) 
unreliable that it is unclear how best to pursue our values. In part this is only to be expected: doing good applied philosophical work has proved difficult, even in areas such as bioethics, where a large amount of applied work has been done over a long period of time. ${ }^{7}$

\section{Private Intellectual Property And Moral Rights}

One key contribution that philosophers can make to thinking about regulation is the simple distinction between rights and goals. If each citizen has a right to a particular resource or freedom, then the duty holder of the right must secure that particular freedom or resource for each individual to whom the right applies. Rights are highly resistant to aggregation: the fact that many people have their rights fulfilled does nothing to reduce the claims of those who do not. Goals give governments general directions for policy, but they do not require a government to guarantee to each individual any particular freedom or resource. So long as a government is pursuing a goal diligently and fairly, no citizen has a legitimate individualised complaint about not being supplied with the good at which the policy aims. ${ }^{8}$

Rights in the sense I am using them are moral rather than legal rights: legal rights are those rights that exist under a given legal system, whilst moral rights are those rights that morality requires us to recognise. ${ }^{9} \mathrm{We}$ are interested in this section in whether there is a moral right to own intellectual property (clearly there is a legal right to hold a copyright on a book, or to hold a patent); and we are also interested in whether legal rights to own intellectual property

7 I provide an analysis of why policy oriented bioethics is so difficult in J. Wilson, 'Towards a Normative Framework for Public Health Ethics and Policy,' Public Health Ethics 2(2) (2009): 184-194. There I argue that philosophers and bioethicists have tended to underestimate the complexity of social systems, and the difficulties involved in reforming them. Once we understand this, then we see that the problems involved in reforming complex institutions are orders of magnitude more complex than is implied or presupposed by simplistic attempts to go from, for example, Mill's harm principle plus a few facts to a claim about how we should regulate a new technology.

8 For this way of drawing the distinction between rights and goals, see for example, T. M. Scanlon, 'Rights, goals, and fairness,' Erkenntnis 11(1) (1977): 81-95. I write more on the concept of rights in J. Wilson, 'Rights', in Principles of Healthcare Ethics, ed. R. Ashcroft, A. Dawson, H. Draper and J. McMillan (London: John Wiley \& Sons, Ltd, 2007).

9 In the context of IP, the term 'moral rights' is potentially ambiguous, as it is also used for legal rights which accrue particularly to authors, such as the right of attribution and the right not to have one's work bowdlerised. In this chapter I shall reserve the term 'moral rights' solely for rights with a moral as opposed to a legal justification. 
might violate moral rights such as the right to healthcare or the right to life. ${ }^{10}$

Making this distinction between rights and goals does not yet commit us to the claim that there are any rights. Rather, it points up how two different types of consideration can play different roles in the justification of public policy. Some kinds of reasons act as exclusionary: even if a goal were otherwise worth pursuing, it would be wrong to pursue the goal if it involved violating a consideration which was highly resistant to aggregation. Obviously, given this conception of rights, we should start by ensuring that-in whatever policy we adopt - we are not violating anyone's rights. We should select our policies only from the set of those ways of regulating that do not violate rights.

There are four different permutations with regard to the rights of those who create intellectual property, and those who make would use it. (I shall use 'the inventor' to refer to the person who creates a piece of IP, and 'the user' to refer to the person who wants to make use of it).

\section{Rights in intellectual property policy}

\section{Both have moral rights.}

The inventor has a moral right to own IP, and the user also has some moral right or moral rights that would be infringed if we allow extensive private ownership of intellectual property.

\section{Only users have moral rights.}

The inventor does not have a moral right to own IP, and the user has some moral right or moral rights that would be infringed if we allow extensive private ownership of intellectual property.

\section{Only inventor has a moral right.}

The inventor has a moral right to own intellectual property, and the user does not have any moral rights that would be infringed if we allow extensive private ownership of intellectual property.

\section{Neither users nor inventors have moral rights. \\ The inventor does not have a moral right to own intellectual property, and the user does not have any moral rights that would be infringed if we allow extensive private}

10 As I shall be using the concept of moral rights, moral rights commit us to the claim that moral rights enjoy some sort of (possibly defeasible) priority over non rights based claims. Of course this is not the only way we can coherently think about rights. Whilst this 'rights as trumps' view can be disputed in as much as many of the legal rights we do recognise are not particularly morally weighty, I shall not enter into the murky waters of the conceptual analysis of rights here. This is because the basic normative claims could be made without reference to rights: those who are worried by the idea of rights as trumps should be able to replace references to rights without loss with the phrase morally important claims of individuals which ground at least reasonably stringent duties to those individuals. I use the term rights simply because it is rather less unwieldy than this construction. 
If case (1) obtained, we would have to think through IP policy through the lens of the philosophical discussion of conflicts of rights. ${ }^{11}$ If case (2) obtained, we would expect the inventor's right based claims to take precedence over the claims made by the users of the IP: the inventor's claims would be claims of rights, whilst those of the users would be of something less than rights. If case (3) correctly described the situation with regard to IP, then we should expect users' needs to constrain what would otherwise be reasonable systems of incentives. If case (4) correctly described the situation with regard to IP, then we should see IP policy as a way of trying to reach towards certain yet to be specified socially valuable goals, without having to negotiate major side constraints.

I argue that neither of the first two options correctly describe the normative situation, because there cannot be any intrinsic moral rights to own intellectual property. Hence the normative situation we face is either one where no one has any relevant rights, or one where only users do. I shall then argue that it is possible for private ownership of intellectual property to wrong people. The upshot is that case (3) describes the normative situation: whilst private ownership of intellectual property is never required in order to respect moral rights, stringent private intellectual property regimes may wrong people, if they prevent them from getting access to goods that they have a right to.

\subsection{Ruling out options (1) and (2): there cannot be a moral right to own intellectual property}

It is sometimes argued that, just as labouring on unowned physical property can give the labourer a moral right to own the object laboured on, so labouring on ideas which were previously part of the intellectual commons can give rise to a moral right to own the resulting ideas. ${ }^{12}$ For instance, it might be thought that in writing a novel, someone transforms elements which are part of the stock of the intellectual commons-such as archetypal plots and characters - and in transforming these materials creates something new which she has a moral

11 See for example J. J. Thomson, The realm of rights (Cambridge: Mass.: Harvard University Press, 1992); F.

M. Kamm, Intricate Ethics: Rights, Responsibilities, and Permissible Harm (Oxford: Oxford University

Press, 2007), chapter 9.

12 By the intellectual commons, I mean the set of all the ideas, theories and mental constructs which are open to all to use. The intellectual commons excludes all ideas which are subject to private intellectual property. It includes any ideas which are (a) currently deemed inadmissible for intellectual property protection (such as mathematical algorithms, scientific theories, natural languages); (b) those ideas which are potentially admissible for intellectual property protection, but which have not yet been claimed as private property; and (c) ideas which were subject to intellectual property protection but which no longer are because the maximum term of intellectual property protection for them has expired (such as Dickens' novels). 
right to exclude others from. If this thought were correct, then it would be wrongful to treat such a work as part of the commons without the author's permission: doing so would breach her rights.

I have argued at length elsewhere that arguments of this kind for moral rights to own intellectual property are unconvincing; and that there cannot be any pre-legislative moral entitlements to own intellectual property. ${ }^{13}$ The essence of this argument is that we cannot simply multiply moral rights ad infinitum: we cannot claim that there is a moral right to $\mathrm{X}$ without providing a moral explanation or justification of why we should recognise such a right. All attempts to justify moral rights must be subjected to what I call the Rights Justification Principle.

Any justification of an intrinsic moral right must show that violating the right would typically result in either a wrongful harm or other significant wrong to the holder of the right, which is independent of the existence of the moral right we are trying to justify.

The problem for any putative moral right to own intellectual property is that we do not seem to be able to explain how the inventor would be wrongfully harmed or otherwise wronged by unauthorised copying of her work unless we already presuppose the existence of the very right we are trying to justify. For there are only three plausible ways in which someone might be wronged by the unauthorised copying of her published work in a way that meets the criterion set down by the Rights Justification Principle:

1. The creator is wronged by being excluded from the use of what she has created.

2. The creator is wronged by being prevented from excluding others from what she has created.

3. The creator is wronged by others benefiting unfairly from her creative effort.

However, none of these putative justifications could plausibly ground a right to own intellectual property, for the following reasons.

(1) is unconvincing because usage of a nonrival good cannot deplete it or stop anyone else from using it. And so a fortiori unauthorised use of a nonrival good cannot prevent the author from using it. Therefore, merely making unauthorised use of the work cannot prevent her from using the work, and thus cannot be the basis for a claim that the inventor's intrinsic moral rights have been violated.

(2) is unconvincing because being prevented from making money by excluding others from access to one's work does not constitute a wrongful harm or other significant wrong which is independent of the (putative) intrinsic moral right to exclude others from access to one's work. It is only if we presuppose the right whose existence we are trying to justify that it

13 See J. Wilson, 'Could There be a Right to Own Intellectual Property?' Law and Philosophy 28(4) (2009):

393-427; J. Wilson, 'Ontology and the Regulation of Intellectual Property', The Monist 93 (2010): 450-463. 
seems plausible to claim that being prevented from charging others for access to one's creation is a wrong to the inventor.

(3) is unconvincing because - assuming there are no pre-existing agreements in placebenefiting from another's effort is unfair only where so benefiting imposes a cost on the person providing the benefit. Making use of an inventor's idea does not impose a cost on her, and so is not unfair.

I conclude that none of 1-3 provide any justification for thinking that there is an intrinsic right to own intellectual property. Nor are there any other plausible wrongful harms or other wrongs caused merely by unauthorised copying which are independent of the existence of the (putative) intrinsic moral right to exclude others from copying and use of one's creations. ${ }^{14}$ It follows that the legal right to make money by excluding others from access to one's work cannot be an intrinsic moral right. As Jefferson put it, 'Inventions then cannot, in nature, be a subject of property. Society may give an exclusive right to the profits arising from them, as an encouragement to men to pursue ideas which may produce utility, but this may or may not be done, according to the will and convenience of the society, without claim or complaint from anybody. ${ }^{15}$

\subsection{The 'No Hardship' Argument}

It is sometimes argued that it is impossible to wrong anyone by asserting private ownership of ideas which would not have existed but for the inventor. On this view, where someone has created something new out of goods which were part of the intellectual commons (say by writing a novel, or creating a new drug), no one can claim to be wronged if the person keeps the new idea private and charges money for access to it. The basic thought is that in so doing the author leaves those excluded no worse off than they would otherwise have been, and so cannot wrong them. As Mill puts it, 'It is no hardship to any one, to be excluded from what others have produced: they were not bound to produce it for his use, and he loses nothing by not sharing in what otherwise would not have existed at all. ${ }^{, 16}$ Call this, following Waldron, the no hardship argument. ${ }^{17}$ I shall argue (in agreement with Waldron) that this argument is not sound.

14 I allow that there may be reasons stemming from the importance of privacy to allow authors to prevent the publication of works that they do not want released to public scrutiny. But once an author has made a work public, she does not have a moral right to exclude others from the use of this idea.

15 T. Jefferson, Letter to Isaac McPherson (13 August 1813), in The Writings of Thomas Jefferson, ed. A. E. Bergh (Washington D.C.: The Thomas Jefferson Memorial Association of the United States, 1907), vol. 13, pp. 333-35. Also available at http://etext.lib.virginia.edu/toc/modeng/public/JefLett.html.

16 J. S. Mill, Principles of political economy: with some of their applications to social philosophy, (5th ed.. London: Parker, Son, and Bourn, 1862), II.2.26.

17 J. Waldron, 'From Authors to Copiers: Individual Rights and Social Values in Intellectual Property',

Chicago-Kent Law Review 68 (1993): 841-887, at pp. 862-868. 
The no hardship argument makes the assumption that if someone is left no worse off than she would otherwise have been, she cannot have been wronged. However it does appear to be possible to wrong someone even if one does not leave her worse off than she would otherwise be. Suppose that Jill is drowning, in an isolated location. Fred notices her as he's zooming past in his speedboat. He does not turn around, reasoning that as she's no worse off than she would have been if he hadn't stopped, he can't have wronged her. This seems monstrous. It is an open question whether we should say that Fred harms Jill in this circumstance; but it seems overwhelmingly plausible to say that he wrongs her. So he either wrongs her without harming her, or wrongfully harms her despite the fact that she ends up no worse off than she would have been had he not been passing. ${ }^{18}$

When a drug comes onto the market which provides the only treatment for a painful and debilitating condition, and the company which holds the patent on the drug uses its monopoly power to charge very high prices and thereby excludes nearly everyone in developing countries from getting access to the drug, the situation may be relevantly similar to the speedboat case. We might think that if there is a moral right to access essential medicines, then the fact that someone would be no worse off than if the company had not invented the drug, is not enough to show that he is not wronged.

Whilst it seems plausible to say that intellectual property restrictions can violate rights, it is much less plausible to think that any and every restriction will do so: if the good which is protected by intellectual property rights does not serve a serious need (like a new type of coffee grinder), or if an existing item in the intellectual commons could perform substantially the same task, then the case for rights violation is weak. ${ }^{19}$ It is only where the good from which the person will be excluded is of substantial importance, and where the good cannot be substituted for one from the commons that it seems plausible to think that IP regulation will violate rights.

18 The concept of harm is surprisingly slippery. Intuitively, A harms B if A makes B worse off than B would otherwise have been. But it is difficult to spell out what the standard is against which we should judge 'would otherwise have been'. There seem to be two basic kinds of answer: either we specify it in terms of a nonnormative baseline, or we specify it in terms of a normative baseline. Both can cause problems, and it is far from clear that a single baseline (whether normative or non-normative) can capture all of our intuitive judgements about when one person harms another. For further discussion, see Wilson, 'Could There be a Right to Own Intellectual Property?'; J. Feinberg. Harmless Wrongdoing (The Moral Limits of the Criminal Law) (Oxford: Oxford University Press, 1990). S. Wilkinson, Bodies for Sale: Ethics and Exploitation in the Human Body Trade (London: Routledge, 2003), pp. 56-71.

19 For example, many new drugs are ‘me-too' drugs are designed to be substantially similar to existing drugs in action and effect. If the patent has lapsed on the original drug, it seems much less plausible to say that anyone's rights are violated if they are priced out of gaining access to the me-too drug. 


\section{The appropriate goals of intellectual property regulation}

Restricting access to ideas which it would be legitimate for people to know is not good in itself. $^{20}$ Where it is pursued, it must be for the sake of some other goal. ${ }^{21}$ The standard answer-and in fact the only answer with any currency, once we rule out intrinsic moral rights to own IP-is that the goal of IP regulation is to promote the beneficial effects of human creativity.

I understand the 'beneficial effects of human creativity' in a broad sense, to include both the beneficial effects for consumers of having more products on the market that will meet their needs and preferences, and the beneficial effects for current and future creators who will be able to draw on the results of more human creativity. ${ }^{22}$ Human creativity in this broad sense encompasses new scientific ideas, new inventions, new films, computer programs, plant varieties and so on.

Human creativity is clearly extremely important for the future of human society: it is through such creativity that we have raised living standards over time; and it will be through such human creativity that we will attempt to improve our living conditions in the future. Whilst human creativity has also had substantial negative effects, I shall leave these on one side here. My interest is in a different question: how can attempts to incentivise creativity impact negatively on other goals that societies should have; and when they do, which should

20 There are some bodies of knowledge (for example about how to make dirty bombs) whose wide circulation it would probably be beneficial to prevent. But these bodies of knowledge would in any case be problematic to publish, whether or not someone had IP rights on the work published. The morality clause of the European Patent Convention, namely that 'inventions the commercial exploitation of which would be contrary to “ordre public" or morality’ are excluded from patentability (Article 53a), displays the impotence of IP law here. This clause is not a very effective way of regulating genuinely immoral activity, as refusing a patent is not sufficient to make an activity illegal: if cloning human beings was legal, but we refused to grant patents on such processes, people would still be free to clone human beings. The only thing we would be denying them by denying patentability would be the right to exclude others from so doing.

21 As Penner puts it, 'The right to property is grounded by the interest we have in using things in the broader sense. No one has any interest in merely excluding others from things, for any reason or no reason at all.' James Penner. The Idea of Property in Law, (Oxford: Oxford University Press, 2000), p.70.

22 IP regulation may not so obviously benefit future producers. But this is part of its rationale: patents, for instance, require the patentor to publish a description of how the invention works. The granting of the temporary monopoly is the quid pro quo for making this knowledge public. If there were no patents, then inventors would have a much greater recourse to trade secrets. Trade secrecy has the drawback that people continually have to duplicate effort, as they attempt to solve problems that have already been solved. In the past there have been some quite significant cases of the withholding of information which could have saved lives: for example, the Chamberlen family kept the discovery of the obstetrics forceps secret for more than 100 years, in order to protect their midwifery business. See W. Moore, 'Keeping mum', BMJ 334(7595) (2007): 698-a. 
take precedence? If the benefits of human creativity are more equivocal than might at first be thought, this would strengthen rather than undermine the reasons for being cautious about incentives to creativity which undermine other important goods. So, for the purposes of my argument I shall grant the claim that human creativity is an important force for good, which there are pro tanto reasons to encourage.

There are a number of important goals which can be threatened by restricting access to human creativity. I shall consider three: liberty, making best use of resources, and equality.

Liberty. Ideas are by nature nonexcludable. ${ }^{23}$ If we wish to prevent sharing of ideas, we need to take positive steps, such as erecting digital fences like Digital Rights Management (DRM), or legislating to allow for private ownership of intellectual property. Such steps involve impositions on liberty: they prevent people from being able to do things that they were previously able to do. Such incursions into liberty are problematic for two reasons: first if we think that liberty is a good thing, then reductions of liberty are prima facie bad. Second, it requires us to use the coercive force of the law to criminalise activities which are not wrong in themselves. So whilst liberty is by no means so important that it trumps all considerations, ${ }^{24}$ incursions into liberty do have to be justified: we need to be able to show that allowing people the liberty to perform the proscribed action will be bad in some way.

Making best use of resources. Ideas are by their nature nonrival in consumption. If one person has a good idea everyone can benefit from that idea and build on it, without the original idea being destroyed or degraded..$^{25}$ If we allow someone a monopoly on the supply of a nonrival good, the monopoly holder is able to extract an economic rent from those who buy the product. In a competitive market, prices are kept down by competition: companies will seek to differentiate themselves in the market by offering goods either at a higher quality, or a lower price, with the net result that (in an efficient market) profit margins are low. Where we have a monopoly, there is no reason to think that the price charged for a good will bear any relationship to the marginal cost of production. Governments in general have an obligation to make the best use of their resources, and to prevent monopolies from occurring; both

23 As Jefferson put it, waxing poetical, 'That ideas should freely spread from one to another over the globe, for the moral and mutual instruction of man, and improvement of his condition, seems to have been peculiarly and benevolently designed by nature, when she made them, like fire, expansible over all space, without lessening their density in any point, and like the air in which we breathe, move, and have our physical being, incapable of confinement or exclusive appropriation.' ('Letter to Isaac McPherson')

24 I have written about this in the context of health: J. Wilson and A. Dawson, 'Giving liberty its due, but no more: trans fats, liberty, and public health,' The American Journal of Bioethics 10(3) (2010): 34-36.

25 As we noted earlier, this is quite unlike a commons such as a village green, or fishing the sea. In the cases of these exhaustible commons, there is reason to restrict access, or to have some kind of governance norms to ensure that the resource is not overused. 
obligations are challenged by allowing private ownership of IP. ${ }^{26}$

Equality. Nonrival goods are not capable of scarcity, and are hence capable of being supplied to everyone who desires them. If there is a scarcity in the supply of a given nonrival good, it is because we have elected to create an artificial scarcity. This is different from the case of rival goods where we frequently see 'natural' scarcities. Because of this, ideas as goods have a particular resonance from the perspective of equality. A society of equals is one in which each citizen can look each other in the eye, and think of herself as of equal status to each other person. The goal of a society of equals is undermined where there are goods which have a large effect on the way which social status is negotiated, and which are differentially spread (particularly when this reinforces existing patterns of advantage and disadvantage). Conversely such a society is promoted where there are goods and freedoms which are important for social status which are available to each on conditions of equality. Because ideas matter for human life, and because ideas can be made available to all at only a marginal extra cost, the goal of a society of equals will push us towards open access to ideas.

So in sum, approaching IP regulation from a abstract philosophical perspective should lead us to affirm the following claims:

1. There are no moral rights to privately own intellectual property. We can either grant or not grant such legal rights without wronging inventors.

2. Granting private intellectual property rights may sometimes violate other rights such as the right to life.

3. Denying access to ideas is not good in itself. Denying access to ideas is good only when it serves some further purpose: namely promoting the beneficial effects of human creativity.

4. Restricting access to ideas is in tension with other important goals such as protection of liberty, making the best use of our resources, and equality.

5. Therefore, private intellectual property, where we adopt it as a way of incentivising creativity, should be viewed as a necessary evil. ${ }^{27}$

26 The European Regulation on Orphan Medicinal Products provide a good example of this. (Regulation (EC)

No 141/2000.) When BioMarin was awarded a European orphan licence for amifampridine (Firdapse), 'a slightly modified version of 3,4-diaminopyridine, which is unlicensed but has been used for more than 20 years to treat two rare diseases, Lambert Eaton myasthenic syndrome (LEMS) and congenital myasthenic syndrome,' price rises were enormous. Treatment for a patient with diaminopyridine cost $£ 800$ - 1000 per year, but BioMarin charged £40,000-£70,000 for amifampridine. N. Hawkes and D. Cohen. 'What makes an orphan drug?' BMJ 341 (2010): c6459-c6459.

27 The position is not so dissimilar from that put forward by Macaulay a while ago: "Thus, then, stands the case. 
The next question is what implications these thoughts should have for concrete IP policy decisions.

\section{Balancing rights and goals in intellectual property regulation}

Going from the more abstract theories to concrete and workable policy proposals is something that is difficult even in those fields of applied philosophy such as bioethics where most work has been done. So what I shall be doing in this section will be quite programmatic, and will also be relatively cautious about what the implications of the analysis so far should be for public policy.

We can separate two questions to which we would need to know the answer before we could make helpful IP policy recommendations: an empirical question and a normative one. The empirical question is: what kinds of environments and regulatory regimes foster creativity most effectively? The normative question is: how are the goods of creativity to be weighed against other goods such as liberty and equality? I shall discuss each in turn.

\subsection{Prospects for answering the empirical question}

When we test the safety and efficacy of a new drug, we control the clinical trial through procedures such as random assignment of participants to the different trial arms, double blinding (so that neither the trial participants nor the researchers know who is receiving which treatment), power calculations (estimating how large a sample size is required to show a statistically significant effect) and placebo controls. A well designed clinical trial thus gives us a high degree of confidence that perceived differences in effects between the two trial arms are caused by differences between the interventions trialled and not some other factor.

It is impossible to perform similarly rigorous tests of the effectiveness of different options for the regulation of intellectual property-to consider say the effects of 20 year patent terms against 25 years. First, it would not be feasible to run a randomised trial which allocated some inventors to longer or to shorter patent terms. Those who were randomised to the shorter patent life would inevitably argue that they were not being treated equally under the law. Even leaving this on one side, such a trial would lack a large number of the other features which allow us to control clinical trials.

The closest we can get to a rigorous empirical test is a natural experiment: we can

It is good that authors should be remunerated; and the least exceptionable way of remunerating them is by a monopoly. Yet monopoly is an evil. For the sake of the good we must submit to the evil; but the evil ought not to last a day longer than is necessary for the purpose of securing the good." Thomas Babington Macaulay, speech delivered in the House of Commons (February 5, 1841), in The Life and Works of Lord Macaulay: Complete in Ten Volumes, Edinburgh ed. (Longmans, 1897), vol. VIII, p. 198. 
investigate past changes in IP regulation, and then see the effects that followed in their wake. However such experiments are so uncontrolled that it is difficult to draw reliable conclusions from them. It is clear that we would not be able to attribute all of any changes of rates of innovation to changes in the regulation of private intellectual property, given that there are many factors which affect how much people are willing to invest in research and development such as tax breaks, the overall state of the economy, what they think their competitors are likely to be doing and how copyable products are without intellectual property protection. How much of any improvements in innovation rates are caused by the change in IP legislation will be deeply contestable. There will be two further deep problems we would need to solve before taking such natural experiments seriously: first there is the problem of measuring creativity. Should we adopt an objective metric such as numbers of patents filed, or number of films released; or should we also focus on the quality of innovations? Second, even if we were to know that, an intervention such as extending the length of the patent term from 20 years to 25 years had a beneficial effect on creativity in one country, it would not follow from this that increasing the length of the patent term would have similarly beneficial effects for our society now. Public policy does not work in such a straightforward and linear way. ${ }^{28}$

What all this means is that what empirical evidence we do have of the effects of different systems of IP regulation lacks rigour - and is certainly not the kind of evidence on the basis of which anyone should feel comfortable about making wide ranging choices about the future of societies. We also have economic models of how creativity is best incentivised. Obviously, for the reasons we have just mentioned, it is extremely difficult to test these models empirically, and perhaps unsurprisingly, these economic models have have wildly different implications, depending on the value orientations of their proponents. Burk and Lemley identify five main economic models in the literature on patents: prospect theory, competitive innovation, cumulative innovation, the anticommons, and patent thickets. Each of these incorporates different assumptions about the kinds of infrastructure and incentives system needed for optimal innovation. Prospect theory assumes that patents should operate like prospects in mining: having IP rights gives companies an incentive to invest more in research and development in the area of their patent in order to reap the benefits of this. This way of looking at innovation implies that "only strong rights to preclude competition will effectively encourage innovation", and that hence "patents should be granted early in the invention process, and should have broad scope and few exceptions' ${ }^{29}$ Competitive innovation theory argues that innovation comes mostly from competition between firms, and that because of this we should ensure that "patent rights should be narrow and should give less than perfect monopoly control. ${ }^{30}$ Cumulative innovation theorists argue that most useful creativity is

28 On the relevant disanalogies between the clinical trial context and the public policy context, see Trisha

Greenhalgh and Jill Russell. 'Evidence-Based Policymaking: A Critique', Perspectives in Biology and Medicine 52(2) (2009): 304-318.

29 Dan L. Burk and Mark A. Lemley. 'Policy Levers in Patent Law', Virginia Law Review 89(7) (2003): 15751696 at p. 1604.

30 Burk and Lemley, 'Policy Levers in Patent Law', p.1607 
additive to already existing inventions, and so that we need to ensure that we do not have a winner-takes-all approach such as the prospect theory approach incorporates, but rather one that allows people to make incremental improvements to products that others have produced. Anticommons theorists focus on the transaction costs involved in licensing multiple patents, and use this as a way of arguing that fundamental innovation platforms should be available freely for innovation. ${ }^{31}$ Theorists of patent thickets focus on the problems of overlapping patent claims, and argue that patent claims should be narrower, or the nonobviousness requirement should be made more stringent. ${ }^{32}$

There is no reason to think that one of these models will be optimal for the incentivisation of all inventions. Variables which are relevant to the shape of optimal systems of incentivisation include the cost of bringing a new product to market; the cost of copying versus the cost of invention; and the extent of first mover advantage in a particular market. These costs will vary systematically between industries, and it may well be that an industry such as pharmaceuticals (where it is extremely costly to bring a drug to market, and relatively cheap to copy), would have an optimal system of incentivisation significantly different from that of saucepans.

One apparent solution to this might be to have a more highly differentiated system of intellectual property protection: tailoring the incentives provided to what is required for best innovation in each particular industry. However there are also problems in having highly differentiated systems of incentivisation: we will face problems of categorisation (with incentives to game the system); and challenges from emerging technologies (do we need to be continually inventing new schemes of incentivisation?) Finally, we should not forget that

each new amendment to the patent statute represents an opportunity for counterproductive special interest lobbying... Patent law has some balance today in part because different industries have different interests, making it difficult for one interest group to push through changes to the statute. Industry-specific legislation is much more vulnerable to industry capture. ${ }^{33}$

So it is also unclear that providing a highly differentiated system of patents would be a net gain.

31 For more on anticomons approaches, see M. A. Heller and R. S. Eisenberg. 'Can Patents Deter Innovation?

The Anticommons in Biomedical Research', Science 280(5364) (1998): 698 -701; M. A. Heller. 'The

Tragedy of the Anticommons: Property in the Transition from Marx to Markets', Harvard Law Review 111(3) (1998): 621-688.

32 For patent thicket approaches, see C. Shapiro, Navigating the Patent Thicket: Cross Licenses, Patent Pools, and Standard Setting', Innovation Policy and the Economy 1 (2000): 119-150.

33 Burk and Lemley, 'Policy Levers in Patent Law', p.1637 


\subsection{Prospects of answering the normative question}

The normative question is how we should weigh the goods of human creativity against other goods such as liberty and equality. Clearly, IP regulation must respect moral rights. We have seen how patents on essential pharmaceuticals might violate moral rights in some cases. To the extent that we are dealing with moral rights, the link between abstract theorising and policy is clear. However, we earlier argued that not much of intellectual property policy will in fact come down to judgements about when moral rights are violated. The great majority of policy decisions will come down to decisions about how to rank different potential policies, in the light of the different values embodied by each policy.

We can approach the task of ranking different policies in the light of the values embodied by each policy in a more or a less ambitious way. On the more ambitious approach, we would attempt to work out a once and for all ranking of all the values in play, and then use this to deduce the answer in the particular case. On the less ambitious approach, we find a way of ranking these values in the particular situation we face, even if that does not amount to a solution for all cases.

It is far from clear that the more ambitious approach is possible: in order for it to be possible, what Henry Richardson calls strong deliberative commensurability would have to be the case: there would have to be 'some single norm (or good) such that all the considerations for and against any option in any situation may be adequately arrayed prior to the choice (for purposes of deliberation) simply in terms of the greater or lesser satisfaction of that norm (or instantiation of that good). ${ }^{34}$ Strong commensurability is difficult to combine with value pluralism: if the ways in which equality and liberty are valuable are different from the way that human creativity is valuable, then it is difficult to see how strong commensurability could be true.

The implausibility of strong deliberative commensurability does not entail that it is impossible for philosophers (or anyone else) to make correct judgments about individual policies which involve tradeoffs between different goods. It follows only that there cannot be a single standard in virtue of which we do this. It is unclear that making tradeoffs between competing values in particular contexts and given other constraints is something in which philosophers qua philosophers have particular expertise. Rather, I think we do better to consider these to be fit subjects for deliberative democracy: decidable on the basis of rigorous arguments by all in the community; not just those with specialist philosophical knowledge.

\section{Conclusion}

Private ownership of IP is not required by respect for moral rights. But given the public goods problem in the production of new ideas, it is plausible to think that suboptimal amounts of

34 H. Richardson, Practical Reasoning about Final Ends (Cambridge: Cambridge University Press, 1994), p.104. 
innovation will occur unless incentives are provided. Adopting private property approaches to incentivising production of ideas is in a certain amount of tension with the values of liberty, making best use of resources, and equality; and so if it were possible to get similar amounts of innovation with a common ownership approach to a private ownership approach, there would be reason to prefer the common ownership approach. It is less clear what the policy implications of these normative claims should be, given the paucity and the unreliability of the evidence we have on the effects of different regulatory regimes.

\section{References}

Aybar, S., J. Harlan and W. Lee, 'John Rawls: For The Record,' Harvard Review of Philosophy 1 (1991): 38-48, at p.45. Online at http://www.hcs.harvard.edu/ hrp/issues/1991/Rawls.pdf

Brennan, G. and P. Pettit, 'The feasibility issue,' The Oxford Handbook of Contemporary Philosophy, ed. by F. Jackson and M. Smith (Oxford: Oxford University Press, 2005), pp. 258-279.

Burk, D. and M. Lemley, 'Policy Levers in Patent Law', Virginia Law Review 89(7) (2003): 1575-1696.

Feinberg, J., Harmless Wrongdoing (The Moral Limits of the Criminal Law) (Oxford: Oxford University Press: 1990).

Greenhalgh, T. and J. Russell, 'Evidence-Based Policymaking: A Critique', Perspectives in Biology and Medicine 52(2) (2009): 304-318.

Hardin, G., 'The tragedy of the commons. The population problem has no technical solution; it requires a fundamental extension in morality', Science 162(3859) (1968): $1243-1248$.

Hawkes, N. and D. Cohen, 'What makes an orphan drug?' BMJ 341 (2010): c6459_ c6459.

Heller, M., 'The Tragedy of the Anticommons: Property in the Transition from Marx to Markets', Harvard Law Review 111(3) (1998): 621-688.

Heller, M. and R. S. Eisenberg, 'Can Patents Deter Innovation? The Anticommons in Biomedical Research', Science 280(5364) (1998): 698 -701.

Jefferson, T., 'Letter to Isaac McPherson' (13 August 1813), in The Writings of Thomas 
Jefferson, ed. A. E. Bergh (Washington D.C.: The Thomas Jefferson Memorial Association of the United States, 1907), vol. 13, pp. 333-35. Also available at http://etext.lib.virginia.edu/toc/modeng/public/JefLett.html.

Kamm, F. M., Intricate Ethics: Rights, Responsibilities, and Permissible Harm (Oxford: Oxford University Press, 2007).

Lessig, L., The Future of Ideas: The Fate of the Commons in a Connected World (New York: Vintage, 2002).

Mill, J. S., Principles of political economy: with some of their applications to social philosophy, (5th ed.. London: Parker, Son, and Bourn, 1862).

Moore, W., 'Keeping mum’, BMJ 334(7595) (2007): 698-a.

Ostrom, E., Governing the Commons: The Evolution of Institutions for Collective Action (Cambridge: Cambridge University Press, 1990).

Penner, J., The Idea of Property in Law (Oxford: Oxford University Press, 2000).

Rawls, J., A Theory of Justice, Revised Edition (Oxford: Oxford University Press, 1999).

Richardson, H., Practical Reasoning about Final Ends (Cambridge: Cambridge University Press, 1994).

Scanlon, T. M., 'Rights, goals, and fairness', Erkenntnis 11(1) (1977): 81-95.

Sen, A., 'What do we want from a theory of justice?', Journal of Philosophy 103(5) (2006): 215-238.

Shapiro, C., 'Navigating the Patent Thicket: Cross Licenses, Patent Pools, and Standard Setting', Innovation Policy and the Economy 1 (2000): 119-150.

Thomson, J. J., The realm of rights (Cambridge: Mass.: Harvard University Press, 1992).

Waldron, J., 'From Authors to Copiers: Individual Rights and Social Values in Intellectual Property', Chicago-Kent Law Review 68 (1993): 841-887.

Waldron, J., 'Property and Ownership', The Stanford Encyclopedia of Philosophy (Winter 2010 Edition), Edward N. Zalta (ed.), URL = <http://plato.stanford.edu/archives/win2010/entries/property/>. 
Wilkinson, S., Bodies for Sale: Ethics and Exploitation in the Human Body Trade (London: Routledge, 2003).

Wilson, J., 'Rights', in Principles of Healthcare Ethics, eds. R. Ashcroft, A. Dawson, H. Draper and J. McMillan (London: John Wiley \& Sons, Ltd, 2007).

Wilson, J., 'Towards a Normative Framework for Public Health Ethics and Policy', Public Health Ethics 2(2) (2009): 184-194.

Wilson, J., 'Could There be a Right to Own Intellectual Property?' Law and Philosophy 28(4) (2009): 393-427.

Wilson, J., 'Ontology and the Regulation of Intellectual Property', The Monist 93 (2010): 450-463.

Wilson, J. and A. Dawson, 'Giving liberty its due, but no more: trans fats, liberty, and public health', The American Journal of Bioethics 10(3) (2010): 34-36. 